OPEN ACCESS

Edited by:

Oliver Karam,

Children's Hospital of Richmond at

VCU, United States

Reviewed by:

Suzie Noronha

University of Rochester, United States

Stuart Weisberg

Columbia University Irving Medical

Center, United States

*Correspondence:

Shuxuan Ma

masxfwyy@sina.com

Specialty section:

This article was submitted to

Pediatric Hematology and

Hematological Malignancies,

a section of the journal

Frontiers in Pediatrics

Received: 29 January 2021

Accepted: 04 May 2021

Published: 28 May 2021

Citation:

Guo $K$, Wang $X$, Zhang $H$, Wang $M$, Song $S$ and Ma S (2021) Transfusion Reactions in Pediatric Patients: An Analysis of 5 Years of Hemovigilance

Data From a National Center for

Children's Health in China.

Front. Pediatr. 9:660297.

doi: 10.3389/fped.2021.660297

\section{Transfusion Reactions in Pediatric Patients: An Analysis of 5 Years of Hemovigilance Data From a National Center for Children's Health in China}

\author{
Kai Guo, Xiaohuan Wang, Huimin Zhang, Mengjian Wang, Shanshan Song and \\ Shuxuan $\mathrm{Ma}^{*}$
}

Department of Transfusion Medicine, Beijing Children's Hospital, Capital Medical University, National Center for Children's Health, Beijing, China

Objective: This study aimed to describe transfusion reactions of pediatric patients from a National Center for Children's Health in China and to examine reaction incidents, reaction types by blood transfusion, and the associated blood products resulting in transfusion reactions.

Methods: We compared transfusion reaction rates, among platelets, plasma, and red blood cells (RBCs) using a retrospective analysis of pediatric patients treated with blood transfusion based on data from the National Center for Children's Health (Beijing, China) by a hemovigilance reporting system from January 2015 to December 2019.

Results: Over the past 5 years, 165 reactions were reported, and the overall incidence was 1.35\% (95\% Cl: 1.14-1.55\%; 165/122,652); for each separate year, the incidences were 1.25\% (95\% Cl: 0.76-1.74\%; 25/20,035; 2015), 1.09\%。 (95\% Cl: $0.65-1.52 \%$; 24/22,084; 2016), 1.66\% (95\% Cl: 1.14-2.18\%; 39/23,483; 2017), 1.36\% (95\% Cl: 0.92-1.81\%; 36/26,440; 2018) and 1.34\%o (95\% Cl: 0.93-1.75\%; 41/30,610; 2019). Transfusion reaction incidents by person included 0.37\% (95\% Cl: $0.21-0.53 \%$; 21/56,815) RBCs, 2.98\%o (95\% Cl: 2.33-3.64\%; 79/26,496) platelets and $1.65 \%$ (95\% Cl: $1.25-2.05 \%$; 65/39,341) frozen plasma. According to the analysis by blood products, the incidence of transfusion was $0.34 \%$ o $(95 \% \mathrm{Cl}: 0.20-0.48 \%$; 23/66,958) for RBCs, 3.21\%o (95\% Cl: 2.50-3.92\%; 78/24,318.5) for platelets, and 0.94\%o (95\% Cl: 0.71-1.17\%; 64/67,912) for frozen plasma. Transfusion reactions were most commonly associated with platelets, followed by plasma and RBC transfusions. The types of blood transfusion reactions were mainly allergic reactions (86.67\%) and febrile non-hemolytic transfusion reactions (FNHTRs, 4.24\%). The disease types of pediatric patients with transfusion reactions were concentrated among those with blood system diseases. A total of $80.61 \%$ of children with transfusion reactions had a previous blood transfusion history.

Conclusions: Transfusion reactions are still relatively common in pediatric patients, and additional studies are necessary to address the differences in reaction rates, especially 
allergic and FNHTRs. Robust hemovigilance systems do include a special section dedicated to children will further the understanding of these reactions and trends, and prospective randomized clinical controlled trials may need to be conducted to perform preventive and corrective measures.

Keywords: blood transfusion, pediatric patient, children, transfusion reaction, hemovigilance system

\section{INTRODUCTION}

A century ago, pediatric medicine was defined based on its specialty. However, there remains a deficit of age-appropriate evidence base (1). Children physiology and pathology differ significantly as compared to adults during growth and development $(2,3)$, some indications may be in common with adults, but others are unique to the physiology of infancy or disease processes found only in childhood. Consequently, clinical guidelines used for adult patients are not fully adapted to pediatric patients in terms of product types, modifications, doses, transfusion indications, blood product selections, potential transfusion reactions. However, currently, most of pediatric guidelines and consensus guidance (such as pediatric transfusion) are not completely based on studies and clinical practice of children $(4,5)$.

According to a 2-year cohort study from Peltoniemi et al., there was a significant reduction in mortality when children were treated in pediatric units rather than in adult and child mixed wards (6). In a word, it is necessary to conduct more studies to understand the unique characteristics of the pediatric patient population.

Transfusions are the therapeutic procedures performed in infants and children in many clinical conditions, and are also associated with substantial risks (7), including serious transfusion reactions $[\sim 1 \%(8)]$, such as hemolytic transfusion reactions (9), transfusion-associated circulatory overload TACO (10) and transfusion-related acute lung injury TRALI (11). Understanding the transfusion reactions in pediatric patients for the use of blood products is essential both to pediatricians wishing to optimize transfusion practice and to blood providers needing to plan the provision of blood products for children. However, data describing outcomes and, in particular, transfusion reactions among pediatric patients are lacking (12-15). A retrospective analysis was conducted of 9 children's hospitals and 35 adult hospitals in the United States from Vossoughi et al.'s study (16), which included pediatric and adult patients who had a reported reaction to blood transfusion of any blood component. Compared to adults, pediatric patients had double the rate of transfusion reactions (16). The difference in transfusion reaction rates between children and adults will raise the question of whether blood transfusion of pediatric patients requires a special consideration. However, there are limited reported data on transfusion reactions in Chinese pediatric patient population.

The hemovigilance reporting system is a tool to improve blood transfusion quality, especially blood transfusion safety (17). Data gathering in a hemovigilance reporting system plays a key role in monitoring how changes in transfusion practice affect the incidence and severity of transfusion reactions and ensures patient safety with blood transfusions (18). The national Chinese Hemovigilance Network (CHN) was established and became a member of the International Hemovigilance Network in 2017. The first annual Chinese hemovigilance report was published in 2021 (19). However, the harmonization of data is likely still evolving, particularly in transfusion reactions of pediatric patients.

In this study, we used a hemovigilance reporting system in our hospital to evaluate the incidence, type, and associated blood products resulting in transfusion reactions in children. The aims of our study were to expand the existing knowledge on pediatric patients' responses to blood transfusion based on a hemovigilance reporting system in China and to provide data comparing the relative incidence of various transfusion reactions to all blood products in pediatric patients to better inform clinical doctors of the relative likelihood of reactions with respect to both blood products and patient ages.

\section{METHODS}

\section{Study Design and Patient Selection}

This was a retrospective observational study. The study population was comprised of patients from a National Center for Children's Health of China (Beijing), which is one of the largest general children's hospitals in China. Our hemovigilance reporting system is integrated into the blood transfusion information management system as a general strategy of risk management at the National Center for Children's Health, Beijing, China. There is mandatory reporting of transfusion reactions in the hospital by clinical doctors, and an electronic database was used to store these data.

We performed a retrospective transfusion reaction analysis using information extracted from our hemovigilance reporting system from January 2015 to December 2019. All patients had to meet the following inclusion criteria: age 0 days to 18 years and transfusion reactions following blood transfusions. All of the information was reported with the following personal identifying information masked before reporting: identity document, patient name, birth date, history of blood transfusion, etc.

\section{Transfusion Reaction Case Classification Criteria}

Transfusion reactions are defined based on the $\mathrm{CHN}$ report (19): allergic transfusion reaction, FNHTR, acute hemolytic transfusion reaction (AHTR), hypotensive transfusion reaction (HTR), TACO, TRALI, transfusion-associated dyspnea (TAD), delayed hemolytic transfusion reaction (DHTR), 
delayed serologic transfusion reaction (DSTR), transfusionassociated graft vs. host disease (TA-GVHD), posttransfusion purpura (PTP), transfusion-transmitted infection (TTI) and unknown. The criteria were applied from the United State CDC recommendations (http://www.cdc.gov/nhsn/PDFs/ Biovigilance/BV-HV-protocol-current.pdf) for each reaction.

\section{Blood Product Unit}

One red blood cell (RBC) unit was processed from $200 \mathrm{ml}$ whole blood with an additive solution (usually CPDA-1), leading to a final volume of $160 \pm 10 \% \mathrm{ml}$, a hematocrit of $50-65 \%$ and $\mathrm{Hb} \geq$ $20 \mathrm{~g}$ (RBC in additive solution) or $150 \pm 10 \% \mathrm{ml}$, a hematocrit of $45-60 \%, \mathrm{Hb} \geq 18 \mathrm{~g}$ and leukocytes $\leq 2.5 \times 10^{6}$ (RBC in additive solution leukocytes reduced); the latter RBC units were prestored leukoreduced. These two types of blood components are usually prepared as $\mathrm{RBC}$ products in our blood bank. Plasma was prepared from whole blood and frozen at $-20^{\circ} \mathrm{C}$ or colder within 6 to $8 \mathrm{~h}$ of collection. On average, one unit contained $100 \mathrm{ml}$ from $200 \mathrm{ml}$ whole blood. The plasma was not pathogen-reduced. The concentrated platelet units were manufactured from units of whole blood that had not been cooled $<20^{\circ} \mathrm{C}$. On average, 10 donor units were calculated one unit of platelet treatment, which was equal to one unit of apheresis platelets $(250-300 \mathrm{ml}$, containing $\geq 2.5 \times 10^{11}$ platelets). The concentrated platelets and the apheresis platelets were not leukoreduced and then stored between 20 and $24^{\circ} \mathrm{C}$ for up to 5 days. The apheresis platelets are usually prepared the platelet products in our blood bank. ABOcompatible platelets are usually provided in our medical center.

\section{Statistical Analysis}

Continuous variables are displayed as the median and interquartile ranges (IQRs; min, $\max$ ). Categorical variables are described as frequencies (percentages).

\section{RESULTS}

\section{Characteristics of Pediatric Patients With Transfusion Reactions}

A total of 165 pediatric patients between January 2015 and December 2019 met the inclusion criteria. Among all patients, $21(12.73 \%)$ received at least 0.5 units of RBCs, $78(47.27 \%)$ received at least 0.5 units of plasma and $66(40.00 \%)$ received at least 0.5 units of platelets treatment during their hospitalization. The types of blood transfusion reactions were mainly allergic reactions (urticarial/rash, including 141 cases; anaphylactic shock, including 2 cases), FNHTRs (including seven cases), and unknown reactions (including 15 cases), which main symptoms included tachycardia (including 12 cases), chills (including 10 cases), chest tightness (including six cases) and body shaking (including one case). These diseases of pediatric patients with transfusion reactions were concentrated among children with blood system diseases, including acute lymphoblastic leukemia (including 73 cases), non-Hodgkin's lymphoma (including nine cases), aplastic anemia (including seven cases), hemophagocytic syndrome (including two cases), pancytopenia (including 12 cases) and others, such as Henoch-Schonlein purpura (including nine cases). A total of $80.61 \%$ of children with transfusion
TABLE 1 | Baseline information of pediatric patients with transfusion reactions.

\begin{tabular}{lc}
\hline Characteristics & Values $\boldsymbol{n}$ (\%) \\
\hline Cases of patients included & 165 \\
Age, years & $3(6,9 ; 0.50,14.17)$ \\
Gender & \\
$\quad$ Boys & $118(71.52)$ \\
Girls & $47(28.48)$ \\
Blood products & \\
RBC & $21(12.73)$ \\
plasma & $78(47.27)$ \\
Platelet & $66(40.00)$ \\
Blood groups & \\
A & $34(20.61)$ \\
AB & $12(7.27)$ \\
B & $66(40.00)$ \\
O & $53(32.12)$ \\
Reaction types & \\
Allergic reaction & $143(86.67)$ \\
FNHTR & $7(4.24)$ \\
Unknown & $15(9.09)$ \\
Disease types & \\
Blood system diseases & $103(62.42)$ \\
Others & $62(37.58)$ \\
Blood transfusion history & $133(80.61)$ \\
\hline
\end{tabular}

*Unknown reaction types include coughing, chest tightness, wheezing, abdominal discomfort, chills, tachycardia, body shaking and cyanosis of the lips.

reactions had a previous history of blood transfusion. The cohort characteristics of pediatric patients with transfusion reactions and the distribution of the types as well as the frequency of each reported incident over the past 5 years of our study are summarized in Table $\mathbf{1 .}$

\section{Transfusion Reaction Incidence Reported From 2015 to 2019}

The study calculated the transfusion reaction incidence from 2015 to 2019 , and the overall incidence was 1.35\%o (95\% CI: $1.14-$ $1.55 \%$; $165 / 122,652)$, among which per year it was $1.25 \%$ o $(95 \%$ CI: $0.76-1.74 \%$; 25/20,035; 2015), 1.09\%о (95\% CI: 0.65-1.52\%o; 24/22,084; 2016), 1.66\%o (95\% CI: 1.14-2.18\%; 39/23,483; 2017), $1.36 \%$ (95\% CI: $0.92-1.81 \%$; $36 / 26,440 ; 2018)$ and $1.34 \%$ (95\% CI: $0.93-1.75 \%$; $41 / 30,610 ; 2019)$, respectively, as shown in Figure 1. Transfusion reaction incidents by person included 0.37\% (95\% CI: $0.21-0.53 \%$; 21/56,815) RBCs, $2.98 \%$ o (95\% CI: $2.33-3.64 \%$; 79/26,496) platelets and 1.65\%o (95\% CI: $1.25-$ $2.05 \%$; 65/39,341) frozen plasma as shown in Figure 2A.

A total of 159,188.5 labile blood products were distributed among our hospitalized and outpatient children from 5 years, among which 66,958 were RBC units, 24,318.5 units of platelet treatment and 67,912 units of frozen plasma. The incidence of transfusion reactions was $0.34 \%$ ( $95 \%$ CI: $0.20-0.48 \%$; 23/66,958) for RBCs, 3.21\%o (95\% CI: 2.50-3.92\%o; 78/24,318.5) for platelets, and $0.94 \%$ ( $95 \% \mathrm{CI}: 0.71-1.17 \%$; $64 / 67,912)$ for 
frozen plasma, as shown in Figure 2B. Transfusion reactions were most commonly associated with platelets, followed by plasma and $\mathrm{RBC}$ transfusions.

\section{DISCUSSION}

Blood transfusions are lifesaving therapies and one of the most common procedures performed in hospitals; however, they can result in transfusion reactions, which can be infectious (20) or more commonly non-infectious (21). Although clinicians and transfusion specialists have taken many blood safety measures, transfusion reactions remain an important cause of transfusion patients of the associated high morbidity and mortality (7, 22). Transfusion reactions are defined as adverse reactions, which are undesirable responses or effects in patients temporally associated with the infusion of blood products (23). In general, transfusion reactions include allergic reactions, FNHTR, TRALI, TACO, transfusion-associated dyspnea, hypotensive transfusion reaction, bacteremia, transfusion-related sepsis, delayed serologic transfusion reaction, posttransfusion purpura, TA-GVHD and acute or delayed hemolysis, and isolated hypotension (7). These

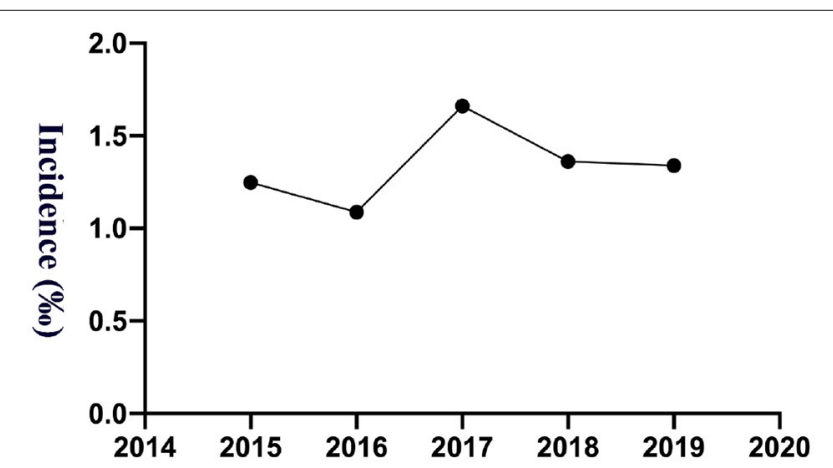

FIGURE 1 | The incidence of transfusion reactions from 2015 to 2019. transfusion reactions can be asymptomatic, mild or potentially fatal. Accurate estimates of transfusion reaction rates, analyses the types of transfusion reactions are essential for effective diagnosis, treatment and prevention.

Hemovigilance is the process of surveillance and alarm during the blood transfusion pathway (24). However, the approaches to hemovigilance are somewhat different between countries, which explains why the results are dissimilar among these different systems, such as India (25), Poland (26), etc. In China, the approaches to hemovigilance are even somewhat different among cities. Actually, it is a legal obligation to report adverse effects of blood transfusions. Our report demonstrated a pediatric hemovigilance system in a National Center for Children's Health in China by analyzing the transfusion reactions reported over a period of 5 years.

Reactions related to infusion of blood products were reported by the clinicians using a standard preformatted form, giving a synopsis of the reaction based on the hemovigilance system. From 2015 to 2019, the transfusion reaction incidence was relatively stable (1.09-1.66\%), still relatively common, but lower than Vossoughi's report (5.38\%o) (16) and Oakley FD's study (6.16\%0) (15) in the United State, De Pascale MR's report $(2.63 \%$ ) in Italy (27), Gauvin F's report for pediatric patients from intensive care units (General pediatrics, Hemato-Oncology, General surgery, Cardiac surgery, Cardiology Gastrohepatology, Orthopedics and Others) (15.94\%o) in Canada (28), Pedrosa AK's report for oncology, general pediatric patients and intensive care units (14.39\%o) in Brazil (29), Hu W's report (8.18\%o) in China (30). It is possible that the age of the pediatric population was differently calculated within age $<21$ (15), 8 to 19 years $(27)$ or 0 to 285.8 months (28) in some reports. In addition, the reported rates of transfusion reactions suffer from high heterogeneity, likely the result of differences in definitions, observational vigilance during blood transfusions, and reporting practice, as well as pathophysiological differences between pediatric patient populations, even among different races. Regardless, the low rate of transfusion reactions means that many studies are under powered for accurate comparisons of products.
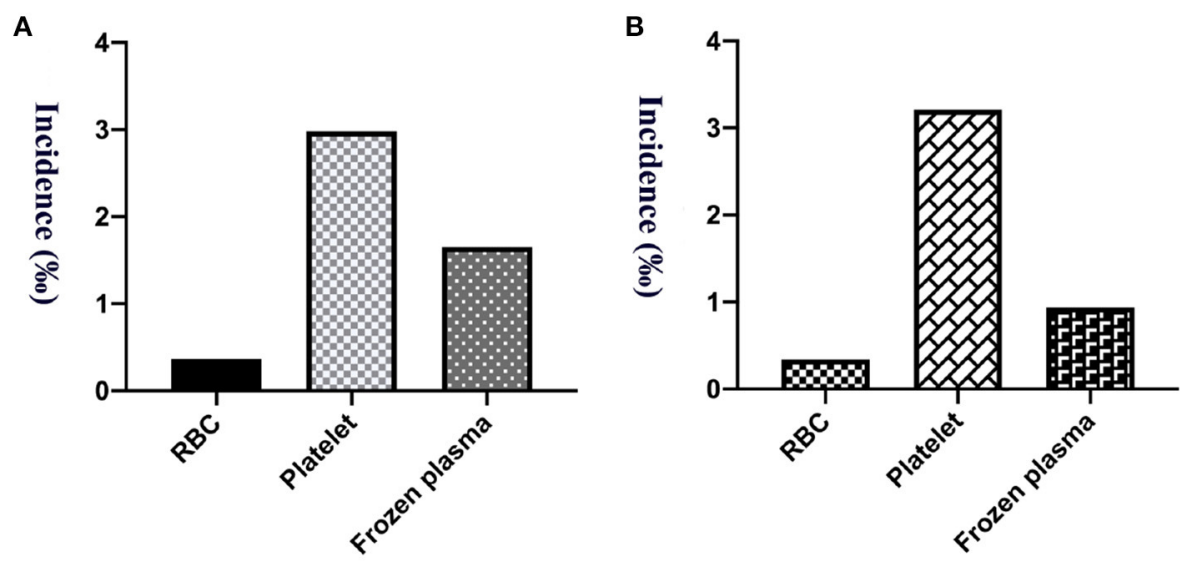

FIGURE 2 | The incidence of transfusion reaction from 5 years of RBCs, platelets and frozen plasma. (A) Per person count. (B) Per blood product count. 
In this study, the types of blood transfusion reactions were mainly allergic reactions and FNHTRs. This was not entirely surprising and as expected, the present results were consistent with the data reported by other researchers $(15,16,23,28$, 31). A single-center investigation reported a significantly higher incidence of transfusion reactions among pediatric patients with FNHTRs, hypotensive transfusion reactions, and allergic transfusion reactions as the main contributors (15). Within the pediatric population, there was an increased incidence of allergic transfusion reactions and FNHTRs compared to the adult population (15). Statistically higher rates of allergic reactions and FNHTRs were previously observed in pediatric patients $(16,31)$. According to the International Hemovigilance Network (INH) database, information was provided on 132.8 million blood components issued in the period 2006 to 2012; among the severe adverse reactions, the most common were allergic reactions (33.4\%) and FNHTRs (32.3\%) (23). Moreover, their transfusion reaction incidence had the similar sex ratio to our report, and reactions were more common in male patients (15). The leucocytes or the mediators from leucocytes may be underlying cause of these two major types of transfusion reactions (allergic reactions and FNHTRs) in the pediatric patient population (31).

According to our reports, platelet units gave rise to more transfusion reactions than frozen plasma and RBCs. Overall, transfusion reactions were most commonly associated with platelets, followed by plasma and RBCs. Kracalik et al. have demonstrated that transfusion reaction incidents were higher among apheresis and pathogen-reduced platelets than apheresis RBCs by quantified transfusion reaction risks based on the data during 2013 to 2018 from the National Healthcare Safety Network Hemovigilance Module in United State, and allergic reactions and FNHTRs were also most common (32). According to Gonzalez DO's report, platelet transfusions were associated with higher risks for postoperative complications in pediatric patients for solid tumors along with volume dependent (33). Saadah et al. (34) evaluated 7 years of annual aggregate hemovigilance data from 23 countries on plasma transfusion reactions. Plasma transfusions can result in relatively high rates of transfusion reaction incidents. Moreover, the most commonly reported plasma transfusion reactions are allergic reactions (IQR: $5.6-72.2$ reactions $/ 10^{5}$ units transfused), FNHTRs (09.1), TRALI, and TACO (34). A total of $80.61 \%$ of children with transfusion reactions had a previous history of blood transfusion. The diseases of pediatric patients with transfusion reactions were concentrated among those with blood system diseases in our center. These results are basically consistent with the data reported by Yanagisawa et al. (31) and $\mathrm{Hu}$ et al. (30). Allergic transfusion reactions were significantly more frequent in children with hematological and malignant diseases and children who received higher number of blood transfusions $(30,31)$. A detailed analysis of some of the transfusion reaction incident reports is necessary. It can reveal complex deviations and/or failures of the procedures in place in the hospital, allowing for rapid advice and implementation of corrective and preventive measures, to improve blood transfusion safety.
In summary, blood transfusions are important supportive care in pediatric patients, but transfusion reactions are also the problem, long-term monitoring of blood transfused patients are essential. Our data provide insight into pediatric transfusion reactions. Future studies are necessary to address the differences in transfusion reaction rates, especially allergic reactions and FNHTRs, and to further address blood transfusion practices in unique and vulnerable populations. That is to say, additional studies are necessary to clarify transfusion reactions in the pediatric patient population. Simultaneously, the national hemovigilance system is important and needs to choose among several strategies for blood product needs based in part on comparative transfusion safety. It is also important that improve knowledge level of blood transfusion safety among pediatricians $(35,36)$ for quickly recognize transfusion reaction, stop the blood transfusion, evaluate and support the patient.

There are several limitations need to be mentioned in this study. First, the national CHN was founded in 2017 (19), so harmonization of data is likely still evolving. Therefore, our study also only provided a single-institution retrospective observational report on pediatric transfusion reactions. Second, blood products that were irradiated or leukoreduced were not well-characterized. Third, the cohort of transfusion reactions was characterized but no information was provided about the baseline patient population receiving transfusions at the hospital. Fourth, there may be some blood transfusion reactions that have not been recognized and reported by pediatricians. Recognizing accurately and reporting transfusion reactions to the Blood Bank or Department of Transfusion Medicine in the hospital are important part of ensuring blood transfusion safety and supporting hemovigilance efforts. Fifth, there was no grading of the severity of the transfusion reactions.

\section{DATA AVAILABILITY STATEMENT}

The raw data supporting the conclusions of this article will be made available by the authors, without undue reservation.

\section{ETHICS STATEMENT}

The studies involving human participants were reviewed and approved by The Ethics Committee of Beijing Children's Hospital, Capital Medical University. Written informed consent from the participants' legal guardian/next of kin was not required to participate in this study in accordance with the national legislation and the institutional requirements.

\section{AUTHOR CONTRIBUTIONS}

KG wrote the drafts of the manuscript, performed the statistical analyses, and reviewed and revised the manuscript. KG, $\mathrm{XW}, \mathrm{HZ}, \mathrm{MW}, \mathrm{SS}$, and SM contributed to the acquisition of data. SM coordinated and supervised data collection 
and entry and critically reviewed the manuscript. All of the authors contributed to the article and approved the submitted version and agreed to be accountable for the results published.

\section{FUNDING}

The project was supported by the Cultivation Fund of Capital Medical University (No. PYZ19033), the Children's Medicine

\section{REFERENCES}

1. Klassen TP, Hartling L, Craig JC, Offringa M. Children are not just small adults: the urgent need for high-quality trial evidence in children. PLoS Med. (2008) 5:e172. doi: 10.1371/journal.pmed.0050172

2. Adeli K, Higgins V, Nieuwesteeg M, Raizman JE, Chen Y, Wong SL, et al. Biochemical marker reference values across pediatric, adult, and geriatric ages: establishment of robust pediatric and adult reference intervals on the basis of the Canadian Health Measures Survey. Clin Chem. (2015) 61:104962. doi: 10.1373/clinchem.2015.240515

3. Nezelof C, Seemayer TA, Bridge JA. Contributions of pediatrics and pediatric pathology to the body of knowledge regarding human disease. Human Pathol. (2010) 41:309-15. doi: 10.1016/j.humpath.2009.06.017

4. New HV, Berryman J, Bolton-Maggs PH, Cantwell C, Chalmers EA, Davies T, et al. Guidelines on transfusion for fetuses, neonates and older children. $\mathrm{Br} \mathrm{J}$ Haematol. (2016) 175:784-828. doi: 10.1111/bjh.14233

5. New HV. Transfusion in neonates and older children: Principles and updates. Transfus Clin Biol. (2019) 26:195-6. doi: 10.1016/j.tracli.2019.07.003

6. Peltoniemi OM, Rautiainen P, Kataja J, Ala-Kokko T. Pediatric intensive care in PICUs and adult ICUs: a 2-Year cohort study in Finland. Pediatr Crit Care Med. (2016) 17:e43-9. doi: 10.1097/PCC.0000000000000587

7. Delaney M, Wendel S, Bercovitz RS, Cid J, Cohn C, Dunbar NM, et al. Transfusion reactions: prevention, diagnosis, and treatment. Lancet. (2016) 388:2825-36. doi: 10.1016/S0140-6736(15)01313-6

8. Hendrickson JE, Roubinian NH, Chowdhury D, Brambilla D, Murphy EL, $\mathrm{Wu} \mathrm{Y}$, et al. Incidence of transfusion reactions: a multicenter study utilizing systematic active surveillance and expert adjudication. Transfusion. (2016) 56:2587-596. doi: 10.1111/trf.13730

9. Panch SR, Montemayor-Garcia C, Klein HG. Hemolytic transfusion reactions. N Engl J Med. (2019) 381:150-62. doi: 10.1056/NEJMra1802338

10. Bosboom JJ, Klanderman RB, Migdady Y, Bolhuis B, Veelo DP, Geerts BF, et al. Transfusion-associated circulatory overload: a clinical perspective. Transfus Med Rev. (2019) 33:69-77. doi: 10.1016/j.tmrv.2019.01.003

11. Semple JW, Rebetz J, Kapur R. Transfusion-associated circulatory overload and transfusion-related acute lung injury. Blood. (2019) 133:1840-53. doi: 10.1182/blood-2018-10-860809

12. Slonim AD, Joseph JG, Turenne WM, Sharangpani A, Luban NL. Blood transfusions in children: a multi-institutional analysis of practices and complications. Transfusion. (2008) 48:7380. doi: 10.1111/j.1537-2995.2007.01484.x

13. Chang TT. Transfusion therapy in critically ill children. Pediatr Neonatol. (2008) 49:5-12. doi: 10.1016/S1875-9572(08)60004-2

14. Miller MR, Elixhauser A, Zhan C. Patient safety events during pediatric hospitalizations. Pediatrics. (2003) 111:1358-66. doi: 10.1542/peds.111.6.1358

15. Oakley FD, Woods M, Arnold S, Young PP. Transfusion reactions in pediatric compared with adult patients: a look at rate, reaction type, and associated products. Transfusion. (2015) 55:563-70. doi: 10.1111/trf.12827

16. Vossoughi S, Perez G, Whitaker BI, Fung MK, Stotler B. Analysis of pediatric adverse reactions to transfusions. Transfusion. (2018) 58:609. doi: $10.1111 /$ trf.14359

17. de Vries RR, Faber JC, Strengers PF. Board of the International Haemovigilance N. Haemovigilance: an effective tool for improving transfusion practice. Vox Sang. (2011) 100:607. doi: $10.1111 /$ j.1423-0410.2010.01442.x
Research Project of Beijing Children's Hospital, Capital Medical University (Nos. YZQN202003 and YZYB202004).

\section{ACKNOWLEDGMENTS}

We are grateful to acknowledge Lijuan Qiu, Hua Shao, Qian Liu, Xiaoyan Fu, Yu Liu, Shuaihang Zhang, and Zijian Niu from Beijing Children's Hospital, Capital Medical University for helpful suggestions in this project.

18. Roubinian N, Kleinman S. Building consensus: steps toward standardised haemovigilance reporting. Lancet Haematol. (2019) 6:e339-40. doi: 10.1016/S2352-3026(19)30081-X

19. Yin Y, Tian X, Li L, Kong Y, Wang J, Lin F, et al. First annual report of Chinese haemovigilance network. Vox Sang. (2021). doi: 10.1111/vox.13059. [Epub ahead of print].

20. Busch MP, Bloch EM, Kleinman S. Prevention of transfusion-transmitted infections. Blood. (2019) 133:1854-64. doi: 10.1182/blood-2018-11833996

21. Goel R, Tobian AAR, Shaz BH. Noninfectious transfusion-associated adverse events and their mitigation strategies. Blood. (2019) 133:18319. doi: 10.1182/blood-2018-10-833988

22. Savinkina AA, Haass KA, Sapiano MRP, Henry RA, Berger JJ, Basavaraju SV, et al. Transfusion-associated adverse events and implementation of blood safety measures-findings from the 2017 National Blood Collection and Utilization Survey. Transfusion. (2020) 60 (Suppl 2):S10-6. doi: 10.1111/trf.15654

23. Politis C, Wiersum JC, Richardson C, Robillard P, Jorgensen J, Renaudier $\mathrm{P}$, et al. The International Haemovigilance Network Database for the surveillance of adverse reactions and events in donors and recipients of blood components: technical issues and results. Vox Sang. (2016) 111:40917. doi: $10.1111 /$ vox. 12447

24. Decadt I, Costermans E, Van de Poel M, Kesteloot K, Devos T. A haemovigilance team provides both significant financial and quality benefits in a University Hospital. Transfus Apher Sci. (2017) 56:199205. doi: 10.1016/j.transci.2016.11.006

25. Boparai JK, Singh S. Hemovigilance: a new beginning in India. Int J Appl Basic Med Res. (2015) 5:200-2. doi: 10.4103/2229-516X.165379

26. Letowska M, Przybylska Z, Piotrowski D, Lachert E, Rosiek A, Rzymkiewicz L, et al. Hemovigilance survey of pathogen-reduced blood components in the Warsaw Region in the 2009 to 2013 period. Transfusion. (2016) 56 (Suppl 1):S39-44. doi: 10.1111/trf.13330

27. De Pascale MR, Belsito A, Sommese L, Signoriello S, Sorriento A, Vasco M, et al. Blood transfusions and adverse acute events: a retrospective study from 214 transfusion-dependent pediatric patients comparing transfused blood components by apheresis or by whole blood. Ann Ist Super Sanita. (2019) 55:351-6. doi: 10.4415/ANN_19_04_08

28. Gauvin F, Lacroix J, Robillard P, Lapointe H, Hume H. Acute transfusion reactions in the pediatric intensive care unit. Transfusion. (2006) 46:1899908. doi: 10.1111/j.1537-2995.2006.00995.x

29. Pedrosa AK, Pinto FJ, Lins LD, Deus GM. Blood transfusion reactions in children: associated factors. J Pediatr. (2013) 89:400-6. doi: 10.1016/j.jpedp.2012.12.012

30. Hu W, Feng L, Li M, Li T, Dai Y, Wang X. Platelet concentrate and type II IL-1 receptor are risk factors for allergic transfusion reactions in children. Ital J Pediatr. (2020) 46:109. doi: 10.1186/s13052-020-00869-6

31. Yanagisawa R, Shimodaira S, Sakashita K, Hidaka Y, Kojima S, Nishijima F, et al. Factors related to allergic transfusion reactions and febrile nonhaemolytic transfusion reactions in children. Vox Sang. (2016) 110:37684. doi: 10.1111/vox.12373

32. Kracalik I, Mowla S, Basavaraju SV, Sapiano MRP. Transfusion-related adverse reactions: Data from the National Healthcare Safety Network Hemovigilance Module-United States, 2013-2018. Transfusion. (2021) 61:1424-34. doi: 10.1111/trf.16362 
33. Gonzalez DO, Cooper JN, Mantell E, Minneci PC, Deans KJ, Aldrink JH. Perioperative blood transfusion and complications in children undergoing surgery for solid tumors. J Surg Res. (2017) 216:129-37. doi: 10.1016/j.jss.2017.04.025

34. Saadah NH, van der Bom JG, Wiersum-Osselton JC, Richardson C, Middelburg RA, Politis $\mathrm{C}$, et al. Comparing transfusion reaction risks for various plasma products - an analysis of 7 years of ISTARE haemovigilance data. Br J Haematol. (2018) 180:727-34. doi: 10.1111/bjh.15082

35. Sahmoud S, Ashry EM, El Kalioby M, Kamel N. Knowledge improvement of blood transfusion safety among pediatricians: post educational intervention. Transfus Med Rev. (2021). doi: 10.1016/j.tmrv.2021. 03.002. [Epub ahead of print].

36. Schaffhausser Filho CJ, Faria JCP, Suano-Souza FI, Sarni ROS. Red blood cell prescription and recognition of transfusion reactions by pediatricians.
Einstein. (2020) 18:eAO5446. doi: 10.31744/einstein_journal/2020 AO5446

Conflict of Interest: The authors declare that the research was conducted in the absence of any commercial or financial relationships that could be construed as a potential conflict of interest.

Copyright (c) 2021 Guo, Wang, Zhang, Wang, Song and Ma. This is an open-access article distributed under the terms of the Creative Commons Attribution License (CC $B Y)$. The use, distribution or reproduction in other forums is permitted, provided the original author(s) and the copyright owner(s) are credited and that the original publication in this journal is cited, in accordance with accepted academic practice. No use, distribution or reproduction is permitted which does not comply with these terms. 